\title{
A Study on the Evacuation Time Considering Elderly's Walking Speed Change According to the Gradient in Flood Disaster
}

\author{
Yoon-ha Lee ${ }^{1}$, Won-hwa Hong ${ }^{2}$ and Ji-soo Lee ${ }^{3}$ \\ ${ }^{1}$ PhD student, School of Architectural, Civil, Environmental and Energy Eng., \\ Kyungpook National University, 80, Daehak-ro, Buk-gu, Korea \\ ${ }^{2}$ Professor, School of Architectural, Civil, Environmental and Energy Eng., \\ Kyungpook National University, 80, Daehak-ro, Buk-gu, Korea \\ ${ }^{3}$ Assistant Professor, Department of Disaster Prevention and Safety Doctor of \\ Engineering, Gyeongju University, 188, Taejong-ro, Gyeongju-si, \\ Gyeongsangbuk-do, Korea \\ 1dldbsgk123@naver.com,2*hongwh@knu.ac.kr, ${ }^{3}$ Iris9972@naver.com
}

\begin{abstract}
Korean society is rapidly entering an aging societyowing to the dectine in fertility rates. As the elderly who are vulnerable to disasters increase, the probability that disaster damage has lead to casualities is growing. Especially, in case of water disaster, while people need to evacuate from low areas to high areas due to nature of diaster, there is resitrction in moving depending on the slope and travel didstance for the elderly.

Therefore, this study aims to analyze the evoculation time of the elderly considering the slope in order to respond to storm and flood related disasters which occupy the most part in Korea.
\end{abstract}

Keywords: Flooding, Walking Speed, Gradient, Elderly, Evacuation Time, GIS

\section{Introduction}

\subsection{Background and Purpose of the Study}

It is a trend that recent damages caused by natural disasters become diversified and large. Therefore, to protect the life and property of citizens, effective prevention and response policy are necessary. Meanwhile, currently $13.1 \%$ of the total population in Korea is the elderly population with 65 or older and it's expected to be entering to aged society where $14 \%$ of the total population is 65 or older in 2018 and then a super-aged society where one of five people in the total population is the elderly people in 2026. Therefore, as the elderly who are vulnerable to disasters increase, the probability that disaster damage has lead to casualities is growing. Especially, in case of water disaster, whil people need to evacuate from low areas to high areas due to nature of diaster, there is restrition in moving depending on the slope and travel didstance for the elderly. Actually, while 270 casualites occurred in 2002 due to the diaster such as typhoon, "Rusa", etc., the elderly with 61 years old or older accounted for 127 people $(47 \%)$.

Therefore, this study aims to analyze the evaculation time of the elderly considering the slope in order to respond to storm and flood related disasters which occupy the most part in Korea. 


\subsection{Scope and Methods of the Study}

The provisions related to shelter in flooding was investigated and previous studies on the change in walking speed by slope and the walking speed by age were reveiwed. In this study, the elderly over 60 years old was taken as the subject of study and the study was conducted based on the latest experimental data among data from previous stuidies. As it's difficult to run actual experiment due to the nature of the elderly, in this study, the walking speed by slope was estimated by using the trend equation based on the prior experimental data. The target area which has a flooding experience was selected, evacuation route to shelter was set by using Arc GIS and evacauation time of the elderly over 60 years old was caculated by considering the slope of each evacuation route.

\section{Gait Characteristic of the Elderly and Standard of Establishment for Flooding Disaster Shelters}

\subsection{Gait Characteristics of the Elderly}

The percentage that walking occupies in the entire transportation since $20 \mathrm{~s}$ increases gradually and it's $40 \%$ in 60 s and $50 \%$ in 70 s so that waing is a very important transportation method for the elderly. However, walking speed is slow and sensory abilities such as vision, hearing, etc. are deteriorated 6 that the ability to predict risks falls and the capability of accident avoidance is reduced due to the aging leg muscles.[3] According to a previous study [4], the limit of walking time is suggested by age such as 10.64 mins in 60 69 years ôld, 10.24 mins in 70 79 years old and 8.3 mins in more than 80 years old.

Among the cases of East Japan big earthquake Rituations in 2011, 'Investigation Results of Damage caused from Tsuname which was from East Japan Big Earthquake(3rd reports)' reported that the average of actual walking speed after tsunami warning was $2.3 \mathrm{~km} / \mathrm{h}(0.64 \mathrm{~m} / \mathrm{s})$. The average distance to shelter was $438 \mathrm{~m}$, and average arrival time taken was $\mathbf{1} .2$ minutes. Furthermore, in the case of evacuating with the eldeny or children, the average of actual walking speed after tsunami warning was $1.88 \mathrm{~km} / \mathrm{h}(0.52 \mathrm{~m} / \mathrm{s})$. [8]

It's presumed in actual situations, the average of adult's walking speed is slower than usual speed because of a lot of unexpected situations and state of disorder.

Table 1 Walking Speed According to a Gradient [2]

\begin{tabular}{|c|c|c|c|c|c|c|c|c|c|c|c|c|}
\hline Course & Group & 1 & 2 & 3 & 4 & 5 & 6 & 7 & 8 & 9 & 10 & $\mathrm{AVG}$ \\
\hline \multirow{3}{*}{$\begin{array}{c}\text { Slope } \\
0\end{array}$} & Group1 & 2.56 & 2.63 & 3.06 & 2.49 & 2.70 & 2.11 & 2.33 & 2.13 & 1.81 & 2.42 & 2.47 \\
\hline & Group21 & 2.31 & 2.09 & 2.20 & 2.45 & 2.08 & 1.70 & 2.07 & 1.99 & 1.92 & 1.95 & 2.08 \\
\hline & Groun3 & 1.74 & 1.85 & 1.78 & 1.84 & 1.58 & 1.92 & 1.90 & 1.80 & 1.72 & 1.85 & 1.80 \\
\hline \multirow{3}{*}{ Slope } & Goupl & 2.65 & 2.26 & 2.69 & 2.70 & 2.42 & 1.71 & 2.31 & 1.74 & 1.76 & 1.79 & 2.20 \\
\hline & Group2 & 2.31 & 2.09 & 2.20 & 2.45 & 2.08 & 1.70 & 2.07 & 1.99 & 1.92 & 1.95 & 2.08 \\
\hline & Group3 & 1.61 & 1.55 & 1.61 & 1.53 & 1.39 & 1.42 & 1.60 & 1.54 & 1.59 & 1.72 & 1.55 \\
\hline \multirow{3}{*}{$\begin{array}{l}\text { Slope } \\
10^{\circ}\end{array}$} & Group1 & 2.24 & 2.03 & 2.26 & 2.16 & 2.20 & 1.48 & 2.09 & 1.38 & 1.72 & 1.48 & 1.90 \\
\hline & Group2 & 2.01 & 1.69 & 1.74 & 1.91 & 1.60 & 1.52 & 1.80 & 1.82 & 1.75 & 1.72 & 1.76 \\
\hline & Group3 & 1.37 & 1.39 & 1.26 & 1.25 & 1.38 & 1.49 & 1.28 & 1.28 & 1.49 & 1.51 & 1.37 \\
\hline \multirow{3}{*}{$\begin{array}{l}\text { Slope } \\
15^{\circ}\end{array}$} & Group1 & 2.09 & 2.12 & 1.92 & 2.03 & 2.06 & 1.36 & 2.03 & 1.34 & 1.39 & 1.49 & 1.78 \\
\hline & Group2 & 1.93 & 1.46 & 1.66 & 1.57 & 1.50 & 1.43 & 1.62 & 1.60 & 1.50 & 1.46 & 1.57 \\
\hline & Group3 & 1.92 & 1.19 & 1.21 & 1.39 & 1.39 & 1.21 & 1.27 & 1.23 & 1.15 & 1.26 & 1.26 \\
\hline
\end{tabular}


Table 2. Priorities of Disaster Response for the Elderly [9]

\begin{tabular}{|c|c|c|c|}
\hline Classification & $\begin{array}{c}\text { Elder who lives } \\
\text { alone }\end{array}$ & $\begin{array}{c}\text { The couple of old } \\
\text { people }\end{array}$ & $\begin{array}{c}\text { Elder who live } \\
\text { with people }\end{array}$ \\
\hline Health elder & 4 & 5 & 6 \\
\hline Weak elder & 1 & 2 & 3 \\
\hline
\end{tabular}

Table 3. Walking Range of According to a Gradient [4]

\begin{tabular}{|c|c|c|c|c|c|}
\hline Age & 3 minutes & 5 minutes & 10 minutes & 15 minutes & $\begin{array}{c}\text { Average } \\
\text { (minutes) }\end{array}$ \\
\hline$\sim 39$ & $2 \%$ & $8 \%$ & $47 \%$ & $43 \%$ & 11.61 \\
\hline $40 \sim 59$ & $2 \%$ & $14 \%$ & $46 \%$ & $38 \%$ & 11.06 \\
\hline $60 \sim 69$ & $3 \%$ & $15 \%$ & $50 \%$ & $32 \%$ & 1064 \\
\hline $70 \sim 79$ & $3 \%$ & $18 \%$ & $52 \%$ & $27 \%$ & 10.24 \\
\hline $80 \sim$ & $10 \%$ & $35 \%$ & $40 \%$ & $15 \%$ & 8.3 \\
\hline
\end{tabular}

The walking of the elderly $=$ Walking time without resistance $\times$ Walking speed

\subsection{Standard of Establishment for Flooding Disaster Shelters}

In the master plan of preliminary and warning alarm of disaster, shelter is to operate by distinguishing into general shelters (performing general-purpose evacuation functions) and special shelters (accommodating people requiring a specialmedical attention).

Table 4. Standard of Establishment for Flooding Disaster Shelters [10]

\begin{tabular}{|c|c|c|}
\hline Category & Standard of establishment & Location of establishment \\
\hline $\begin{array}{l}\text { Flooding } \\
\text { Disaster } \\
\text { Shelters }\end{array}$ & $\begin{array}{l}\text { Flood safety area } \\
\text { (School, Public institution burilding etc.) } \\
\text { Satisfying Medical facilities. Evacuation } \\
\text { facilities for long period } \\
\text { Scale of accommodation } \\
\text { - about } 2000 \sim 8000 \text { people }\end{array}$ & $\begin{array}{l}\text { The Shortest distance outside the } \\
\text { area of flood expectation } \\
\text { - designation or equip in } 1 \mathrm{~km} \text { for } \\
\text { walking } \\
\text { Considering the place that be } \\
\text { designated from city office or } \\
\text { disaster headquarters }\end{array}$ \\
\hline $\begin{array}{l}\text { Special } \\
\text { Disaster } \\
\text { Shelters }\end{array}$ & $\begin{array}{l}\text { Shelters by using for special object of } \\
\text { protection (Hospital etc.) }\end{array}$ & 1 or 2 place in each district \\
\hline
\end{tabular}

3. The Evaluation Distance of Elderly People According to Gradient and Walking Speed through Derivation of Elderly's Walking Speed in Flood Situation

\subsection{Derivation of Elderly's Walking Speed Change According to a Gradient}

Walking speed by slope was estimated for elderly people more than 60 years old by using a linear trend line based on experimental results of prior study [2] and the results are shown in the table below. 


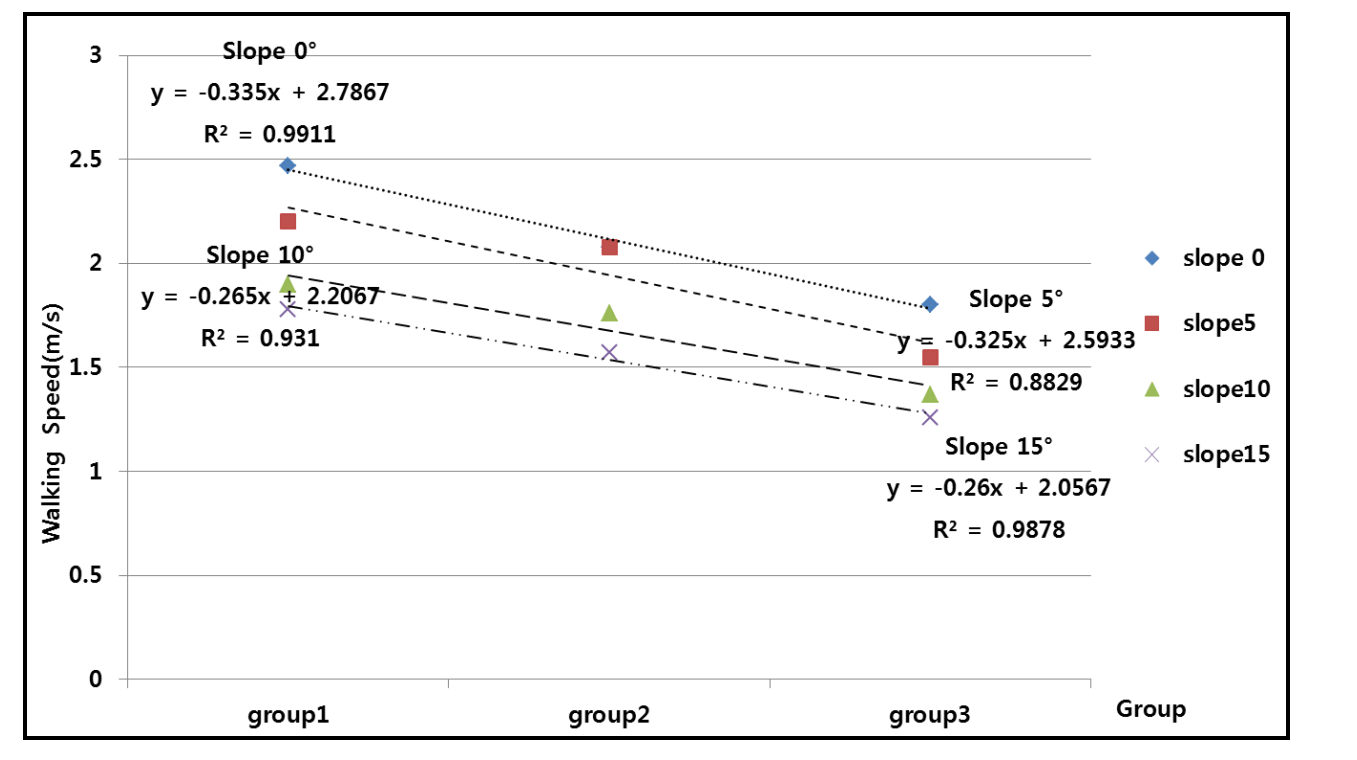

Figure 1. Walking Speed According to a Gradient By Age-Specific Groups [1]

Table 5. Using a Linear Trend Line Based on Experimental Results of Prior

\begin{tabular}{|c|c|c|c|c|}
\hline Category & $\begin{array}{l}\text { Linear trend } \\
\text { line }\end{array}$ & $\begin{array}{c}60 \sim 70 \\
\text { age's } \\
\text { estimated } \\
\text { speed }(\mathrm{m} / \mathrm{s})\end{array}$ & $\begin{array}{l}\text { 70 80 age's } \\
\text { estimated } \\
\text { speed }(\mathrm{m} / \mathrm{s})\end{array}$ & $\begin{array}{l}\text { Over } 80 \text { 's } \\
\text { estimated } \\
\text { speed }(\mathrm{m} / \mathrm{s})\end{array}$ \\
\hline Slope $0^{\circ}$ & $\begin{array}{c}Y=-0.335 x \\
+2.7867\end{array}$ & 145 & 1.11 & 0.78 \\
\hline Slope $5^{\circ}$ & & 1.29 & 0.97 & 0.64 \\
\hline Slope $10^{\circ}$ & & 1.15 & 0.88 & 0.62 \\
\hline Slope $15^{\circ}$ & & 1.02 & 0.76 & 0.50 \\
\hline
\end{tabular}

$\mathrm{G}=$ Gradient $\left(0^{\circ} \rightarrow \mathrm{G}=1,5^{\circ} \rightarrow \mathrm{G}=2,5^{\circ} \rightarrow \mathrm{G}=2,10^{\circ} \rightarrow \mathrm{G}=3, \ldots\right)$

If disabled or evacuation alone is not possible, walking speed is assumed $0.5 \mathrm{~m} / \mathrm{s}$

3.2. The Evacuation Distance of Elderly According To Gradient and Walking Speed in Flood Situation

The evaluation distance of elderly people more than 60 years old can be expressed as Equation 3 by using the walking speed of the elderly and the limit of walking time by age group based on previously derived slope. Based on it, the evaluation distance of elderly people more than 60 years old was derived as shown in Table 5 .

$$
\begin{aligned}
& \mathrm{L}(60 \sim 70)=(-0.1437 \mathrm{G}+1.5850) \cdot \mathrm{T} \\
& \mathrm{L}(70 \sim 80)=(-0.1152 \mathrm{G}+1.2175) \cdot \mathrm{T}
\end{aligned}
$$




$$
\begin{gathered}
\mathrm{L} \text { (over 80) }=(-0.0867 \mathrm{G}+0.8500) \cdot \mathrm{T} \\
\mathrm{G}=\text { Gradient }\left(0^{\circ} \rightarrow \mathrm{G}=1,5^{\circ} \rightarrow \mathrm{G}=2,5^{\circ} \rightarrow \mathrm{G}=2,10^{\circ} \rightarrow \mathrm{G}=3, \ldots\right) \\
\mathrm{T}=\text { Walking time without resistance }
\end{gathered}
$$

Table 6. Elderly People (0ver 60's) Possible Evacuation Distance [1]

\begin{tabular}{|c|c|c|c|}
\hline Category & $\begin{array}{c}60 \sim 70 \text { age's } \\
\text { estimated possible } \\
\text { evacuation distance }\end{array}$ & $\begin{array}{c}70 \sim 80 \text { age's } \\
\text { estimated possible } \\
\text { evacuation distance }\end{array}$ & $\begin{array}{c}\text { Over } 80 \text { 's estimated } \\
\text { speed }(\mathrm{m} / \mathrm{s})\end{array}$ \\
\hline Slope $0^{\circ}$ & 923.57 & 683.03 & 386.80 \\
\hline Slope $5^{\circ}$ & 825.64 & 594.92 & 320.36 \\
\hline Slope $10^{\circ}$ & 732.05 & 541.72 & 307.12 \\
\hline Slope $15^{\circ}$ & 649.06 & 464.92 & 247.36 \\
\hline
\end{tabular}

4. Prediction of the Elderly's Evacuation Time by Considering the Gradient and Distance of the Evacuation Route

\subsection{Status of Shelters For Flooding in the Target Area}

Nogok-dong of Daegu city which has an experience of flooding by heavy rain in July and Auguest, 2010 is selected as a target area for study and the study was conducted. Inundation occurred due to the lack of drainagefacitiy and 80 houses were flooded by an average water depth of $1 \mathrm{~m}$ or more and 80 refugeess occumed. There are three flood shelters in the target area.

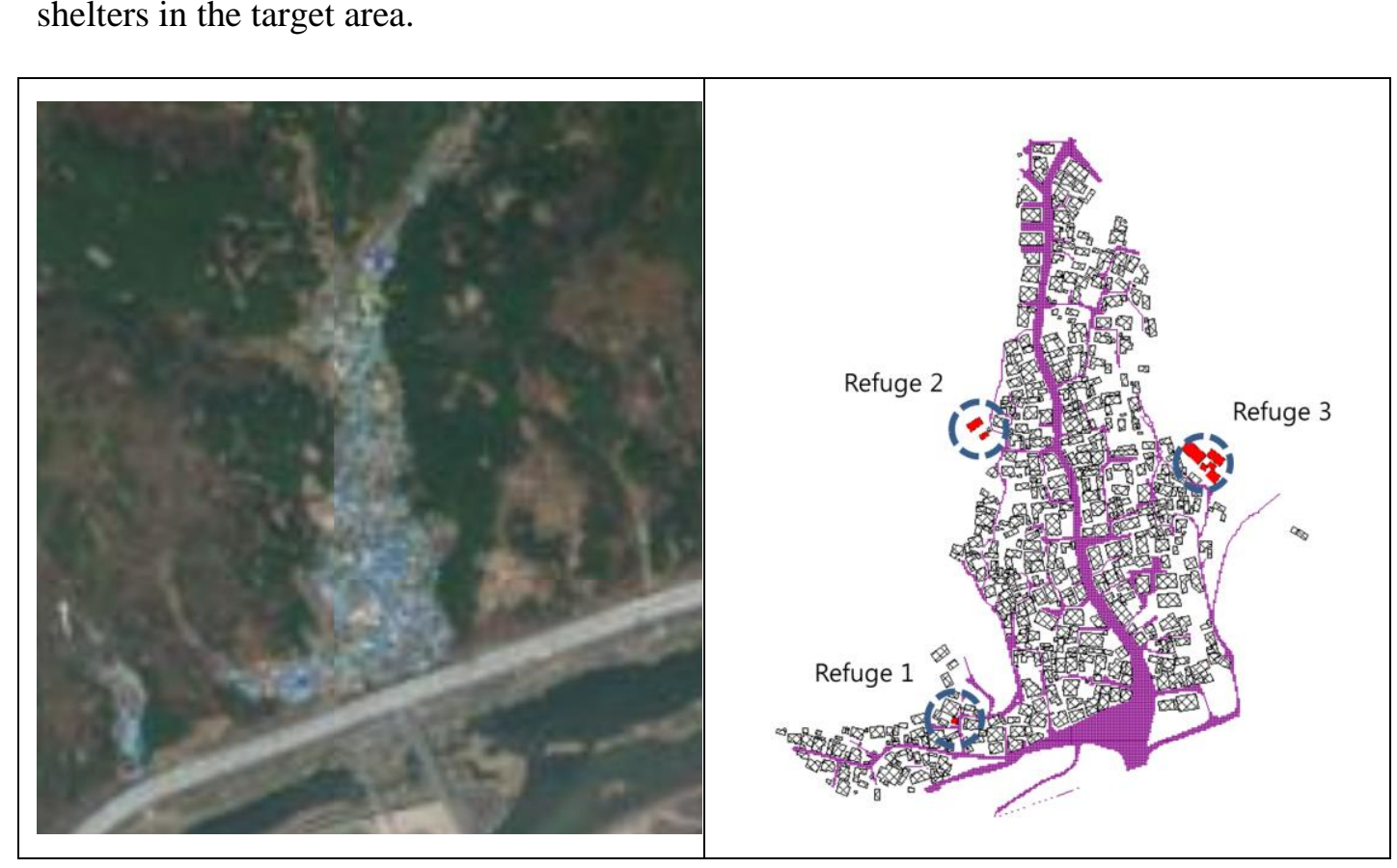

Figure 2. Status of Target Area

4.2. Evacuation Time Analysis by Evacuation Route Considering the Walking Speed of the Elderly

TIN was created and DEM data were generated by using the contour lines of digital map. 
Slope is an angle which is tilted from the ground and caculation is as shown in the following expression.

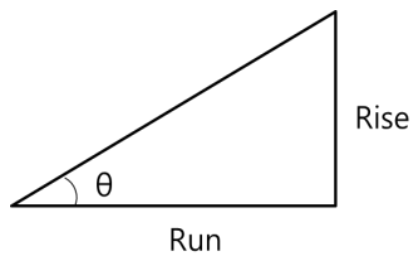

degree $: \tan ^{-1}\left(\frac{\text { Rise }}{\text { Run }}\right)$

Figure 3. Deriving Gradient

Slope was derived by using the spatial analyst based on established DEM data. The shortest routes from the lowest altitude of the target area to three flood shelters are set as evacuation routes by using Network Analyst. Regarding evacuation route, evacuation time was caculated by deriving slope by each $1 \mathrm{~m}$.

The start point was set at the center of the polygon after generating polygon by connecting the points of refuges. And destination point in the analysis of evacuation route was set at 3 refuges.

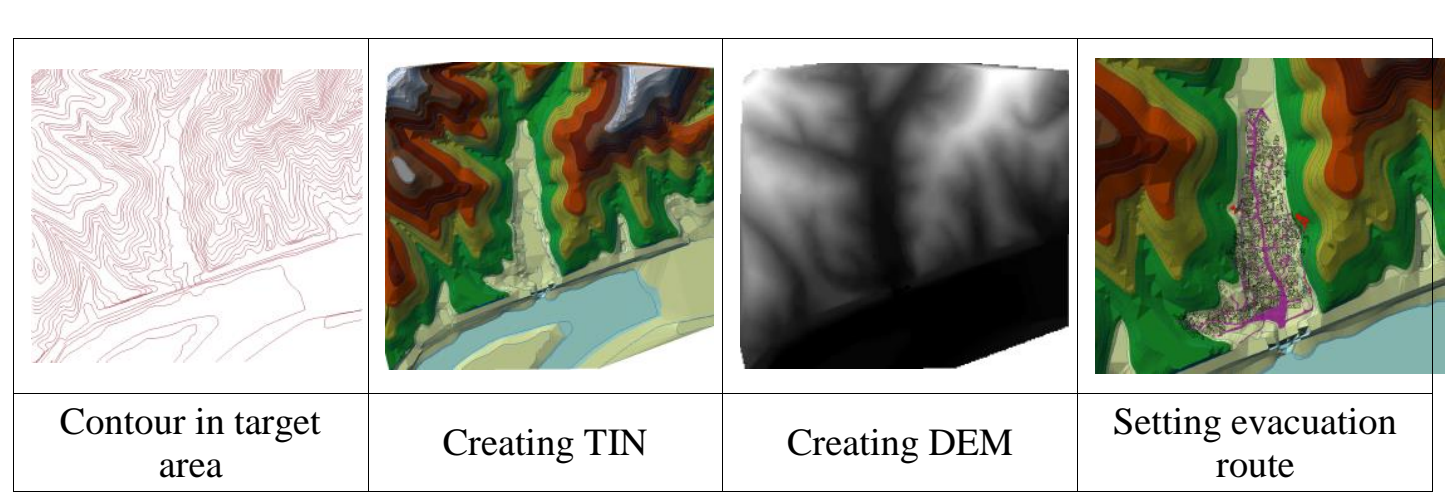

Figure 4 Progress of using GIS

Table 7.Evacuation Distance and Degree According To the Evacuation Route

\begin{tabular}{|c|c|c|c|c|}
\hline \multirow{2}{*}{ Classification } & \multirow{2}{*}{ End Point } & Distance & \multicolumn{2}{|c|}{ Degree $(\theta)$} \\
\cline { 4 - 5 } & & $(\mathrm{m})$ & Maximum & Minimum \\
\hline Route 1 & Refuge 1 & 172.7 & 28.47 & 0.00 \\
\hline Route 2 & Refuge 2 & 201.4 & 18.41 & 0.00 \\
\hline Route 3 & Refuge 3 & 350.9 & 26.45 & 0.00 \\
\hline
\end{tabular}

\section{Table 8. Prediction of the Elderly's Evacuation Time according To the} Evacuation Route

\begin{tabular}{|c|c|c|c|c|}
\hline \multirow{3}{*}{ Classification } & \multicolumn{2}{|c|}{$\begin{array}{c}\text { Non Considering The Decreasing } \\
\text { Rate Of Walking Speed } \\
\text { According To The Gradient }\end{array}$} & \multicolumn{2}{|c|}{$\begin{array}{c}\text { Considering The Decreasing } \\
\text { Rate Of Walking Speed } \\
\text { According To The Gradient }\end{array}$} \\
\cline { 2 - 5 } & Age & Time(sec) & Age & Time(sec) \\
\hline \multirow{3}{*}{ Route 1} & $60 \sim 70$ & 167.29 & $60 \sim 70$ & 119.82 \\
\cline { 2 - 5 } & $70 \sim 80$ & 222.99 & $70 \sim 80$ & 156.67 \\
\cline { 2 - 5 } & $80 \sim$ & 334.33 & $80 \sim$ & 226.25 \\
\hline \multirow{2}{*}{ Route 2} & $60 \sim 70$ & 171.15 & $60 \sim 70$ & 139.74 \\
\cline { 2 - 5 } & $70 \sim 80$ & 226.24 & $70 \sim 80$ & 182.71 \\
\hline
\end{tabular}




\begin{tabular}{|l|c|c|c|c|}
\hline & $80 \sim$ & 333.63 & $80 \sim$ & 263.85 \\
\hline \multirow{3}{*}{ Route 3 } & $60 \sim 70$ & 330.66 & $60 \sim 70$ & 243.46 \\
\cline { 2 - 5 } & $70 \sim 80$ & 439.95 & $70 \sim 80$ & 318.33 \\
\cline { 2 - 5 } & $80 \sim$ & 657.15 & $80 \sim$ & 459.71 \\
\hline
\end{tabular}

\section{Conclusion}

In this study, the possible evacuation distance was derived by considering the walking characteristics of the elderly and the slope of evacuation route. According to the current installation standard, it says the flood shelter is to be installed within $1 \mathrm{~km}$ walking distance from the expected flood area, but the results of the study showed that the walking speed with a higher slope decreases and the limit of walking time with older decreases so that there will be a difficulty to evacuate to a shelter during flooding. Also the evacuation time of the elderly by slope and travel distance of evacuation route is estimated and theres was $22-47 \%$ difference compared to when not considering the slope.

In this study, the walking distance of each age group was estimated and conducted based on the results of previous studies, not measuring the walking speed of elderly people more than 60 years old so that it can be a limitation of this"study Because of a lack of the basic data which can be used to fully reflect the attributed of the elderly in the calculation of the decreasing rate of walking speed-according to the gradient, so it will have to be supplemented by researches on experiment on the walking speed by slope for the elderly, change in walking distance by the depth of water, etc. in the future.

\section{Acknowledgments}

This work was supported by the National Research Poundation of Korea(NRF) grant funded by the Korea government(MSIP) (NRF-2016R1A2A1A05005459), (NRF2015R1D1A1A01058785).

\section{References}

[1] Y.-H.Lee, J.-S. Lee and W.-H. Hong, "A Study on the Possible Evacuation Distance for the Elderly considering the slope in order to prepare for Flood Disaster", Advanced Science and Technology Letters, vol. 124, (2016), pp 103-108

[2] Ji-S. Lee and W.-H. Hong, "Upward Evacuation Experiment for Estimating Evacuation Speed in Water Disaster", Adyanced Scien e and Technology Letters, vol. 100, (2015), pp. 97-101

[3] S. Ryu, "Study on construction of barrier-free living zone considering the aged pedestrians", Master thesis, vol. 87, no. 5, (2009).

[4] The Korean Transport Institution, "A study on providing transportation and facility maintenance instruction cônsidering transportation minority", (2000).

[5] National Emergency Management Agency, "A Study on Inundation Analysis including Underground Spaces, (2008).

[6] H.-K. You, E.-S. Kim, J.-S. Lee, S.-Y. Kim and P.-H. Lee, “A Study on Walking Velocity of Old Men jn Korea”, Journal of Korean Insititute of Fire Sci. \&Eng, 2003. vol. 10, (2003), pp. 407-414

[7] -T Han, J.-S. Cho and S.-S. Bae, "The Spatio-temporal Analysis of Gait Characteristics during Ramp Ascent and Descent at Different at Different Inclination", Journal of The Korean Society of Physical Therapy, vol. 18, no. 1, (2006), pp. 95-106.

[8] J.-S. Kwon, D.-H. Yoon and J.-H. Koh, "Analysis of Shelters Acceptable Range According to Evacuation Speed During Flood Disaster by Severe Rain Storm”, Journal Korean Soc. Hazard Mitig., vol. 15, no. 3, (2015), pp. 115-123.

[9] National Disaster Management Institute, "Research and Analysis of Disaster Prevention Measures for Vulnerable Populations in Disasters", (2010).

[10] National Disaster Management Institute, "A study on the Revitalization for Technology in Evacuation and Disaster Relief", (2013). 


\section{Authors}

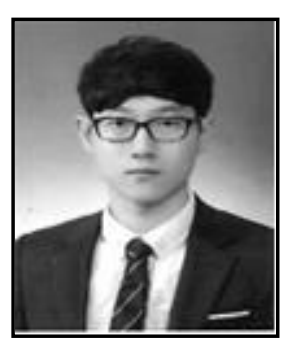

Yoon-Ha Lee, he is a Ph.D. Student, School of Architectural, Civil, Environmental and Energy Engineering, Kyungpook National University, 80 Daehakro, Bukgu, Daegu, Rep. of Korea. dldbsgk123@naver.com

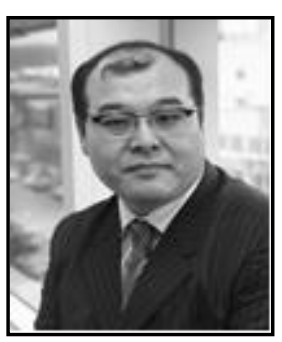

Won-Hwa Hong, he is a Professor, Corresponding author, School of Architectural, Civil, Environmental and Energy Engineering, Kyungpook National University, 80 Daehakro, Bukgu, Daegu, Rep. of Korea. hongwh@knu.ac.kr

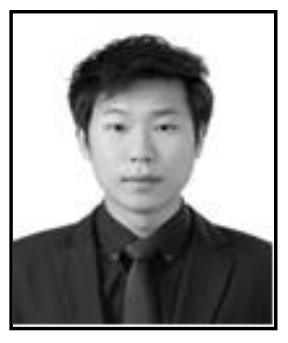

Ji-Soo Lee, he is s Assistant Professor in Department of Disaster Prevention and Safety Dôctor of Engineening, Gyeongju University, 188, Taejong-ro, Gyeongju-si, Gyeongsangbuk-do, Rep. of Korea. Iris9972@naver.com

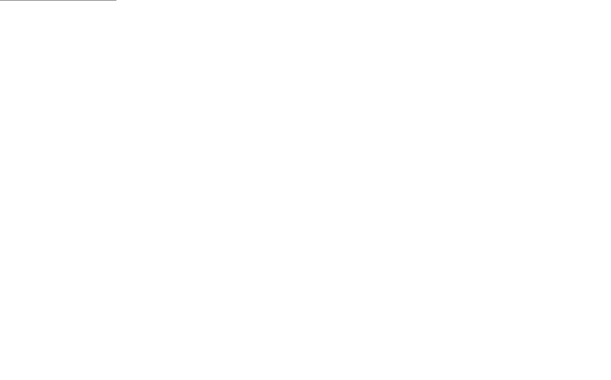

